\title{
ENTRE LA EFICIENCIA Y LA EQUIDAD. LOS DESAFÍOS DE LA REFORMA FISCAL EN BUENOS AIRES. PRIMERA MITAD DEL SIGLO XIX ${ }^{1}$
}

\author{
JORGE GELMAN \\ Instituto Ravignani/Universidad de Buenos Aires/CONICET-Argentina
}

DANIEL SANTILLI

Instituto Ravignani/Universidad de Buenos Aires

\section{RESUMEN}

En 1821 se realiza una reforma fiscal en Buenos Aires de claro carácter modernizador. Se suprimen gravámenes de antiguo régimen y se crea un sistema que si bien incluye los inevitables impuestos al comercio exterior, implanta contribuciones directas a los capitales, con el objeto de disminuir la dependencia de los primeros y distribuir más equitativamente la carga fiscal, imponiendo a los propietarios según sus riquezas.

En este trabajo se reconstruyen las series impositivas, mostrando el escaso peso de la Contribución Directa en el conjunto. Se estudian también diversos intentos de mejorar su recaudación, que fueron fracasando uno tras otro.

Finalmente se analizan las causas de estos fracasos y la lógica que llevó a los gobiernos del período a mantener un sistema impositivo regresivo, pero eficiente y con menores costos políticos.

\footnotetext{
1 Versiones previas fueron presentadas en el Seminario Internacional «La Modernización fiscal en América Latina y el mundo ibérico, siglos XVIII-XX», Lima, octubre 2005, y en el XIV International Economic History Congress, Helsinki, agosto 2006. Agradecemos los numerosos comentarios recibidos, especialmente de los coordinadores de esas reuniones, Carlos Contreras, Luis Jáuregui y Juan Pro Ruiz. También las sugerencias de Luis Bértola y de los evaluadores anónimos de RHE.
} 
Palabras clave: Modernización fiscal, Impuestos directos, Buenos Aires, siglo XIX

\begin{abstract}
In 1821 a clearly modern tax reform was undertaken in Buenos Aires. Ancien Regime taxes were suppressed and it was created a system which included usual assessments related to international commerce, but also direct taxes on capitals, in order to diminish the dependence on duty customs and to distribute the fiscal weight in a more equitable manner, by taxing proprietors in proportion to their wealth.

In these work, we reconstruct fiscal series, showing the little weight of the "Contribución Directa» over fiscal income. Also we study some attempts to improve this tax collection, which failed once and again.

Finally we try to explain those failures and the reasons to maintain a regressive tax system which, nevertheless, was efficient and brought lesser political costs than direct taxes.
\end{abstract}

Keywords: fiscal modernization, direct taxes, Buenos Aires, 19th century

JEL Classification: H21, N26

La crisis del orden colonial en Hispanoamérica plantea un conjunto de desafíos de difícil solución para los espacios políticos que se tratan de constituir en reemplazo del que tenía su centro en España.

La construcción de nuevos Estados que pudieran ejercer el monopolio de la coerción física y simbólica sobre determinados espacios, requería la obtención de legitimidad, pero también de recursos fiscales para sostener todo el andamio burocrático y especialmente militar/policial, en un contexto en que la soberanía política se disputaba cotidianamente en los campos de batalla de las guerras de independencia y civiles, en las fronteras con los indígenas no sometidos al poder criollo, así como en la represión y disciplinamiento de una población soliviantada y en creciente movilización en el marco de las guerras.

Muchas regiones del fenecido imperio debieron repensar totalmente la estructura de sus ingresos fiscales, ya sea por la crisis de algunas actividades económicas que constituían la base de los ingresos del estado bajo el régimen colonial (como es el caso de la minería de plata gravada con los quintos o diezmos, o el comercio interno, gravado por la alcabala y otras gabelas, afectado por las guerras y la ruptura de los espacios virreinales), ya sea por la pérdida de legitimidad de algunos gravámenes como es el caso de tributo indígena que en algunas regiones 
seguía constituyendo todavía uno de los pilares de la fiscalidad a inicios del XIX ${ }^{2}$, etc.

En general en la década revolucionaria la mayoría de los gobiernos recurrieron a fuentes puntuales, como las contribuciones «voluntarias» exigidas a los «leales seguidores» o las «forzosas» obtenidas de los enemigos o sospechosos de tales, que se sumaban a los declinantes recursos tradicionales. Pero es evidente que aquéllas constituían fuentes agotables, irritantes y no seguras para fiscos con necesidades perentorias y abultadas por la situación de guerra e inestabilidad. Por tanto era necesario repensar los sistemas fiscales de manera de establecer fuentes de ingreso regular y con legitimidad que permitieran obtener recursos de modo previsible y a la vez facilitaran la recreación de consensos entre sectores diversos de la población, quienes se expresaban crecientemente a través de los nuevos sistemas de representación, así como se movilizaban cada vez más a través de su participación militar, en intervenciones políticas públicas, etc.

Muchos de los Estados recién creados tuvieron serias dificultades en reconstruir sus ingresos fiscales, dada la crisis de sus economías en el período que sigue a la revolución, o por su incapacidad de establecer la autoridad sobre poblaciones y espacios en disputa. Algunos de ellos sufrieron además la pérdida de las transferencias fiscales que la Corona organizaba desde sus colonias más ricas hacia aquellas con menos recursos a través de los situados.

Muchos gobiernos intentaron, influidos también por las ideologías prevalecientes desde fines del XVIII y puestas sobre el tapete por las Cortes de Cádiz en la década del diez, suprimir los impuestos de tipo corporativo y establecer sistemas de ingresos tributarios más modernos, universales e igualitarios, basados en gravámenes directos que tuvieran relación con los recursos de sus pobladores, que no perjudicaran la expansión del comercio, promovieran el crecimiento económico, a la vez que propendieran a una mayor equidad ${ }^{3}$. De esta manera buscaban limitar también los que dependían del comercio interior y exterior y que además de estar sometidos a las fluctuaciones de esa actividad y la amenaza naval de naciones poderosas, resultaban injustos a los ojos de algunos contemporáneos, por gravar el consumo y por tanto indiscriminadamente a los pobladores más allá de su mayor o menor fortuna.

Sin embargo en la mayoría de los casos estos intentos reformistas conocieron serias dificultades, tanto por la cerrada oposición de los sec-

\footnotetext{
2 Un texto pionero en ese sentido es el de Sánchez Albornoz (1978), que muestra las dificultades que genera la supresión del tributo indígena tras el proceso revolucionario y la necesidad de restaurarlo posteriormente.

3 Ver por ejemplo Jáuregui (2006).
} 
tores pudientes que trataban de eludir todo sistema de imposición directa que los afectara en sus patrimonios o rentas, como por el a veces dificultoso proceso de cobro de estos nuevos impuestos que requerían tanto de un buen conocimiento de los recursos existentes (para lo cual era necesario establecer buenos padrones de población y riquezas), como de una estructura administrativa aceitada y amplia que permitiera cobrar esos impuestos en los distintos ámbitos de la autoridad estatal. Al contrario, los viejos y conocidos impuestos al comercio, que se cobraban ya sea en algunos contados puertos o en las principales plazas de mercado, resultaban sin duda más eficaces, inmediatos y ocultaban mejor su peso, que era más fácil de trasladar a los precios al consumidor que los directos ${ }^{4}$.

En el caso específico del Río de la Plata, la cuestión fiscal no parecía fácil de solucionar en un principio, dado que buena parte de los recursos eran obtenidos durante el período colonial de transferencias realizadas desde el corazón económico del virreinato, el famoso «situado de Potosí», que llegaba año tras año a Buenos Aires, y constituía el principal rubro de sus ingresos.

La década del diez se caracterizó por ingresos irregulares, préstamos y contribuciones forzosas o voluntarias, hasta que hacia 1820, en un Buenos Aires constituido como uno de los Estados autónomos desprendidos del virreinato, se consigue una cierta estabilidad política y se sientan las bases de un nuevo modelo económico fundado en la integración de la región pampeana en los circuitos del comercio internacional, a través de la colocación de los excedentes de una ganadería vacuna organizada en explotaciones extensivas.

${ }^{4}$ Uno de los casos hispanoamericanos mejor estudiado es el mexicano. Contamos con varios trabajos recientes referidos tanto al gobierno federal y a algunos estados particulares en la primera mitad del XIX, como a las finanzas de la experiencia centralista de los 30 y primeros 40. Todos muestran los intentos de remplazar los viejos tributos por sistemas de imposición directa, pero también señalan las enormes dificultades en lograrlo y la vuelta a sistemas que privilegiaban los impuestos indirectos, sobre todo los que gravaban al comercio. Ver por ejemplo los trabajos reunidos en Marichal y Marino (2001) y en Sánchez Santiro, Jauregui e Ibarra (2001). Por su lado, el monumental libro de Fradera (2005) dedicado a los territorios que se mantuvieron bajo la órbita colonial española en el siglo XIX, trata de manera exhaustiva la cuestión fiscal como una de las claves para establecer un equilibrio que fuera aceptable para los intereses de los productores y comerciantes de las colonias, los comerciantes peninsulares y el Estado metropolitano. Analizando por ejemplo el caso cubano señala que el equilibrio logrado se basó en «la irresistible tendencia de las clases altas criollas a preferir las contribuciones indirectas por encima de cualquier otro procedimiento recaudatorio que implicase una medición más precisa de los factores de producción». Y concluye, de manera algo pesimista: «Nada nuevo bajo el sol, ni en Cuba ni en otras partes menos cercanas al trópico». De esta manera los sistemas fiscales privilegiaron las imposiciones indirectas que hacían pesar sobre las espaldas de los consumidores el costo del mantenimiento del nuevo sistema colonial. 
Se inicia así la llamada «Feliz Experiencia», establecida desde la llegada al gobierno del estanciero Martín Rodríguez, con sus ministros Bernardino Rivadavia y Manuel José García, que impulsarán un amplio conjunto de reformas políticas, económicas y fiscales, de inspiración liberal y utilitaria. Entre esas reformas, se encontraba de manera destacada el completo reordenamiento de la estructura fiscal, que buscaba suprimir los gravámenes de antiguo régimen y establecer otros modernos y más equitativos, que le dieran a la vez al Estado porteño los recursos necesarios para afianzar su autoridad y sostener las múltiples iniciativas que se prometía ${ }^{5}$.

En 1821 y sobre la base de un detallado informe del miembro de la Comisión de Hacienda de la Sala de Representantes, Santiago Wilde, se propone una amplia reforma que buscaba limitar la dependencia de los impuestos aduaneros en los recursos fiscales de Buenos Aires, tanto por la voluntad de restringir estas gabelas para promover el comercio más abierto posible, como para eludir la injusticia de unos gravámenes que pesaban indiscriminadamente sobre los consumidores ${ }^{6}$. Otro argumento importante en el texto de Wilde era el riesgo que significaba reposar sobre esos impuestos para un Estado que carecía de una flota de guerra apropiada y cuyos puertos podían ser sometidos por otros a bloqueo, destruyendo de golpe todo su sistema hacendístico (en esto habría de ser profético). La herramienta central que se propone para reemplazar los ingresos aduaneros era la creación de un impuesto directo a las rentas, que incluso fuera progresivo para las mayores. Pero a la vez, Wilde, conciente de las dificultades para mensurar estos ingresos de los particulares, sostiene que esas rentas se pueden deducir de las riquezas poseídas, ellas, sí, más fáciles de controlar. Por tanto propone la creación de la Contribución Directa, un impuesto que se calcularía sobre los capitales poseídos ${ }^{7}$.

${ }^{5}$ Existe una bibliografía que ha tratado de manera consistente los aspectos generales de las reformas económicas y fiscales del período y que ha sido de gran utilidad para este trabajo. Desde Burgin (1960), Nicolau (1980 y 1988), hasta Halperin (1982). La relación entre políticas fiscales, monetarias y desempeño económico en este período ha sido rediscutida recientemente por A. Irigoin en algunos artículos (Irigoin, 2000), aunque no hemos podido acceder a su tesis doctoral inédita. En un trabajo reciente (Irigoin, 2006) discute los intentos de reforma fiscal en Buenos Aires luego de la caída del gobierno de Rosas a mediados del siglo XIX.

${ }^{6}$ El proyecto original de Wilde observaba que «los impuestos sobre los artículos de primera necesidad gravitan desigual, injusta e impolíticamente sobre las clases medianas y pobres». En tal sentido consideraba que el que se aplica al pan es el peor, ya que se consume no "en razón de sus facultades, sino de las bocas de las familias», disminuye la producción de trigo, su consumo, retarda la población del país y aumenta el gasto de mantenimiento de las familias. Estevez (1960): 216, cursiva en el original. En este texto se incluye la propuesta completa de Wilde y el proyecto de la Sala de Representantes.

7 El sustrato de la obra de Wilde es, sin lugar a dudas, el librecambismo en boga, ya que propone limitar al máximo las imposiciones al comercio tanto para las exportaciones como 
Basado en este informe, el 17 de diciembre de 1821 se instaura este nuevo impuesto, la Contribución Directa (en adelante CD) que gravaba los capitales asentados en la provincia. Las tasas a aplicar variaban de acuerdo al siguiente esquema: el giro comercial pagaba el 0,8 por cien, las fábricas el 0,6 por cien, el 0,2 por cien erogarían los hacendados por sus ganados, el 0,1 por cien los agricultores por sus instrumentos de labran$\mathrm{za}$, mientras que cualquier otro bien abonaría el 0,2 por cien ${ }^{8}$. Al año siguiente las tasas sobre ganados y labranzas fueron duplicadas. La ley reconocía exenciones, tal vez basadas en las ideas de Wilde, al fijar una base no imponible diferenciada para casados y solteros de $\$ 2.000$ y de $\$$ 1.000 , respectivamente. Establecía que cada contribuyente debía declarar espontáneamente sus capitales; el Estado recurriría a la regulación por peritos si los montos eran considerados notoriamente disminuidos. Por último se fijaba la moneda de curso legal como medio de pago. Estas dos últimas disposiciones tendrían consecuencias funestas para la recaudación, ya que la primera fomentaba la menor declaración posible al no ser controlada por el Estado y la segunda permitirá, ante la abultada emisión de papel moneda inconvertible desde 1826 y el consecuente proceso de devaluación de ese medio, la licuación de los montos a abonar.

Podemos apreciar en el contenido de estas reformas algunas de las características que se podrían considerar superadoras de las concepciones de antiguo régimen. En primer lugar, el criterio universal de la imposición, ya que no considera exenta a ninguna persona basada en su pertenencia a determinado fuero, función, grupo étnico, etc. En todo caso la incorporación de un mínimo imponible diferenciado para solteros y

para las importaciones. Pero a la vez es de destacar el principio de progresividad, todavía raro para la época. Postulaba que se estableciera un impuesto a los artículos de lujo, como las joyas, de manera de gravar diferenciadamente a los más ricos. También proponía progresividad en las tasas a las utilidades derivadas de los capitales, a las ganancias personales y al empleo de dependientes y la posesión de esclavos. Para las utilidades y ganancias, preveía seis categorías, aumentando el monto a pagar en 1/6 entre cada una de ellas. También aplicaba escalas para los que utilizaban dependientes y esclavos, basadas en la cantidad de personas empleadas Por último, planteaba mantener un equilibrio constante entre las entradas y salidas de la Tesorería General, de manera de inspirar confianza entre la opinión pública, así como «emplear pocas personas en las oficinas, pero las más capaces de despachar con prontitud los negocios». El principio de progresividad finalmente no estará presente en la ley de CD que se termina votando. Ver un análisis de la propuesta en Santilli (2004).

8 Forzando un poco la interpretación se puede decir que estas tasas gravan más fuertemente los capitales que se supone tienen en mayor medida los más poderosos. Aunque no se puede generalizar, la agricultura era más bien una actividad de productores familiares. En el extremo opuesto el comercio aparece más bien asociado a un sector privilegiado. Quizás también influyera en esta tabla una cierta idea fisiocrática de la mayor utilidad social de la agricultura y las actividades de la tierra frente al comercio o aún las manufacturas, que enarbolaba cierta parte de la elite ilustrado-liberal. Ver por ejemplo el escrito de Manuel Moreno en La Abeja Argentina, núm. 1, 15 de abril de 1822, citado por Myers (1995). 
casados, a la vez que le otorga cierto aire de progresividad al gravamen, se la puede considerar como una medida para fomentar la formación de familias ${ }^{9}$. En segundo lugar, el legislador le otorga el carácter de gravamen directo, es decir, en cabeza de las personas y no de los productos o de sus actos económicos. En tercer lugar, se coloca su percepción bajo el ámbito de la administración del Estado, más específicamente en la Secretaría de Hacienda, ingresando en el grueso de la tesorería, sin otro destino prefijado que las rentas del Estado ${ }^{10}$. En ese sentido se desestiman los derechos que permitían que las corporaciones pudieran percibir algún tipo de tributo. Por último, consideraba un único medio de pago, la moneda corriente, dejando de lado el pago en especie, como muchas veces era percibido el diezmo.

En el marco de una relativa pobreza fiscal de las distintas experiencias provinciales argentinas que fluctuaban entre magros ingresos provenientes de impuestos comerciales internos hasta la reimposición del tributo indígena, como en el caso de la pobrísima Jujuy, estas reformas le van a dar a Buenos Aires una salud fiscal notable, con ingresos que superaban al de todas las provincias rioplatenses juntas y que le permitirán al Estado porteño sostener diversas guerras domésticas y externas, la construcción del orden interno en Buenos Aires, así como expandir su influencia sobre el resto de las provincias argentinas ${ }^{11}$.

${ }^{9}$ Ésta es la intención de Santiago Wilde en el texto que fundamenta el proyecto que luego sirve de modelo al decreto.

${ }^{10}$ Esta intención luego va a ser desmentida al entregarse la recaudación a un privado, aunque como veremos no tendrá el sentido de Antiguo Régimen, ya que no se rematará la recaudación, sino que este particular actuará como un agente recaudador que debe rendir cuentas de sus percepciones.

${ }_{11}$ Como señala Juan Carlos Garavaglia en la introducción a la reedición de Guerra y Finanzas, de T. Halperín (Halperin, 1982-2005), en 1841 Buenos Aires tenía un presupuesto de casi dos millones de pesos plata, mientras que Córdoba disponía de 139.000, Corrientes 101.000, Santa Fe 60.000 o Jujuy 14.173 pesos (en este caso en 1840). Calculado en términos per cápita, Córdoba, la segunda ciudad del territorio, podía gastar 1 peso con 3 reales por habitante, mientras Buenos Aires disponía de 12 pesos con 7 reales. No podemos referir aquí todos los trabajos que han abordado la cuestión de las finanzas públicas de los Estados provinciales en esta etapa. Pero se puede señalar que los pocos intentos realizados en las provincias por imponer sistemas de CD fracasaron rápidamente (por ejemplo en Mendoza en los años veinte, o en Córdoba en los cuarenta) y aún en algunos casos ni siquiera fueron propuestos. En casi todos lados las magras finanzas reposaron en viejos impuestos al comercio interior remozados, el control de algunas aduanas «exteriores» (como el caso de Mendoza con Chile), así como mantuvieron hasta muy tarde viejos impuestos coloniales como el diezmo, aunque ahora usufructuados por el Estado. Sólo a la caída de Rosas y tras la firma de la Constitución nacional de 1853, se suprimen las aduanas interiores y se nacionalizan las exteriores, quitando de esta manera sus principales recursos a las provincias. Para compensarlas se trata de implementar sistemas de contribución directa en casi todas, pero con resultados dispares. Se puede ver un resumen de los principales casos provinciales en Cortés Conde (2000). Algunos buenos estudios monográficos en Romano (2002), Chiaramonte (1991); Schmit (2004), Coria (1998). 
Claro que esa salud fiscal estaba lejos de ser regular, y muy lejos de las propuestas que los ideólogos de esas reformas de los primeros 20 pretendían. Éstos habían buscado independizar los ingresos del Estado de Buenos Aires de la aduana, y establecer sistemas de imposición directa sobre la renta y la riqueza. El resultado era que las entradas del fisco porteño se integraban en porcentajes que muchas veces excedían el 80 por cien por los impuestos que se cobraba al comercio exterior, en particular a las importaciones. Y las imposiciones directas recaudaban sumas generalmente minúsculas, a veces irrisorias, pese a los esfuerzos en contrario de los sucesivos gobiernos.

De estos intentos y de su fracaso trata el presente trabajo.

\section{LA IMAGEN DE UN FRACASO EXITOSO: LAS CIFRAS DE LA RECAUDACIÓN FISCAL DE BUENOS AIRES}

En este apartado trataremos de reconstruir la recaudación fiscal del Estado de Buenos Aires en la primera mitad del siglo XIX y evaluar el papel que jugó en ella la CD.

Los montos de recaudación anuales por todo concepto están consignados en el Registro Oficial de Buenos Aires (ROBA) bajo el título de entradas y salidas de receptoría general ${ }^{12}$. Durante algunos años, al principio de la serie, las autoridades no incluían información sobre la gestión de las finanzas del Estado en este Registro; por ello nos encontramos con algunas lagunas, que se repiten en los textos de otros investigadores. Sin embargo, utilizando información dispersa obtenida en diversas fuentes, se puede reconstruir casi la totalidad de la serie ${ }^{13}$. A partir del primer gobierno de Rosas la serie se hace continua, con una excepción, el año 1834, en que sólo se publicó el primer semestre.

Las cifras informadas a partir de 1827 están en pesos papel, por lo que para hacerlas comparables entre sí deben ser homogeneizadas convirtiéndolas en pesos fuertes. Para ello utilizamos la información sobre «valor de un peso fuerte en pesos papel moneda corriente» que proporcionó Juan Álvarez ${ }^{14}$.

Antes de evaluar las cifras debemos hacer varias observaciones, que se convierten en correcciones a las cifras informadas. A partir de que se

12 En trabajos previos se han utilizado las declaraciones de la contribución directa y no lo efectivamente recaudado. Por lo tanto, las diferencias que pueden encontrarse responden a las cifras devengadas para cada año, comparadas con lo efectivamente percibido en cada año. En otros casos tenemos el monto devengado pero no el percibido, como el resumen del año 1825. Véase Gelman y Santilli (2002, 2003, 2004, 2005 y en prensa).

13 En los cuadros correspondientes indicamos el origen de las cifras.

14 Álvarez (1929), pp. 99 y 100. 
diferencia el valor del peso fuerte por sobre el peso papel aparecen ingresos en la receptoría en ambas monedas; sin embargo fueron sumados en el informe como si tuvieran el mismo valor; en ese caso hemos corregido las cifras. Asimismo, en las informaciones publicadas se incluyen ingresos resultado de emisión de moneda como si se tratara de una entrada genuina, o la contabilización de un préstamo, bajo el rubro «remesas de la tesorería general», lo que contablemente se justifica para conjugar el mayor volumen de egresos (y en la práctica el déficit), hecho que hemos corregido ${ }^{15}$. Por último, desde 1835 se reciben valores en diferentes instrumentos de pago como letras, títulos por fondos públicos, etc.; las primeras en su gran mayoría para pagar derechos de aduana, que por supuesto incluimos.

Con respecto a la CD, desde 1839 se informa por separado el valor del impuesto establecido sobre las «consignaciones». Se trata de la parte del giro comercial que los contribuyentes declaraban haber recibido en consignación, de manera que disminuían la tasa de aplicación desde el 0,8 por cien al 0,4 por cien ${ }^{16}$. No encontramos ninguna norma legal que justifique tal procedimiento, por lo que interpretamos que a partir de ese año se tomó por costumbre percibir la parte correspondiente a las importaciones de mercancías en el momento del ingreso, incrementando en los hechos los gravámenes aduaneros. Apoyamos nuestro razonamiento viendo también que se pagaba en sus dos terceras partes con el mismo instrumento que los derechos de aduana, con letras. Por esas mismas razones su ingreso fue afectado por los bloqueos como los derechos de aduana. Según varios investigadores que han estudiado este impuesto, se aplicaba desde varios años antes pero nuestra fuente principal, el ROBA, no lo discrimina. Sin embargo, a partir de diversas fuentes citadas por esos investigadores hemos podido reconstruir los montos de ese rubro percibidos en los años previos.

De tal modo, un cargo que gravaba el capital (en este caso comercial) pasa a gravar directamente el consumo, ya que se incluiría luego en el precio de mercado del bien. Tenemos aquí un buen ejemplo de cómo lograron convertir un impuesto directo en uno indirecto, pasando la carga fiscal de los capitalistas a los consumidores. Por supuesto para el Estado era mucho más sencillo percibir el impuesto de esta forma ya

15 Evidentemente los gastos del Estado que superaron la recaudación que podemos llamar «genuina» se cubrieron con deuda o emisión monetaria. Pero nuestra intención aquí es ver cómo el Estado se financia normalmente, por lo cual dedujimos esas cifras.

16 El consignatario no era propietario de las mercancías que importaba, sino que actuaba a cuenta de un tercero. Es por ello que la ley de CD le aplicaba un impuesto menor, lo que llevó a los comerciantes a reclamar ese status de manera indiscriminada para rebajar sus obligaciones fiscales. Esta práctica es denunciada por diversos agentes del Estado al menos desde la primera mitad de la década de 1830. Ver Estevez (1960). 
que sólo bastaba con reforzar los controles sobre el ingreso de mercadería por el puerto o por las Aduanas secas. En cambio, las declaraciones de los contribuyentes son mucho más difíciles de controlar, porque suponen la creación de un aparato fiscalizador especializado ${ }^{17}$. Volveremos sobre este tema.

La serie completa de las percepciones se incluye al final del artículo como anexo.

Veamos los gráficos 1 y 2 que muestran la recaudación fiscal total del Estado de Buenos Aires y la referida al rubro CD en pesos fuertes y en porcentajes.

GRÁFICO 1

CONTRIBUCIÓN DIRECTA E INGRESOS TOTALES EN PESOS FUERTES

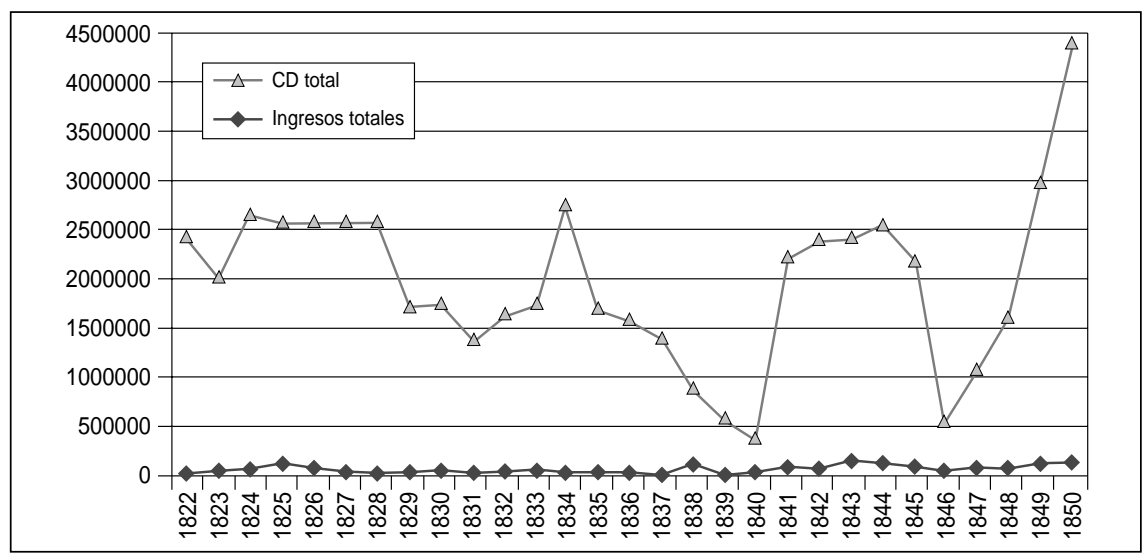

Fuente: Idem Anexo Estadístico.

Como se puede apreciar, la importancia de la CD como ingreso estable del Estado provincial fue siempre muy limitada, si no desdeñable. En sus tímidos inicios apenas llegaba al 1 por cien del total recaudado. En la primera mitad de los años 30 se estabiliza alrededor del 3 por cien, porcentaje que podemos considerar significativo si tenemos en cuenta que se trata del período afectado por una tremenda sequía en 1829/32, calamidad que influyó notablemente en la economía rural porteña ${ }^{18}$. En

17 Evidentemente sigue siendo más sencillo gravar el producto en el momento de ingreso al mercado (derechos aduaneros) o cuando se realizan transacciones con dicho producto como objeto (Impuesto al valor agregado). También sigue siendo más sencillo trasladar su incidencia al consumidor que gravar las rentas o los capitales.

18 Diversos testimonios sobre esta sequía nos muestran que el stock ganadero disminuyó notablemente sobre todo en las zonas donde la carga de animales por hectárea era muy 
GRÁFICO 2

PORCENTAJE DE LA CD SOBRE INGRESOS TOTALES

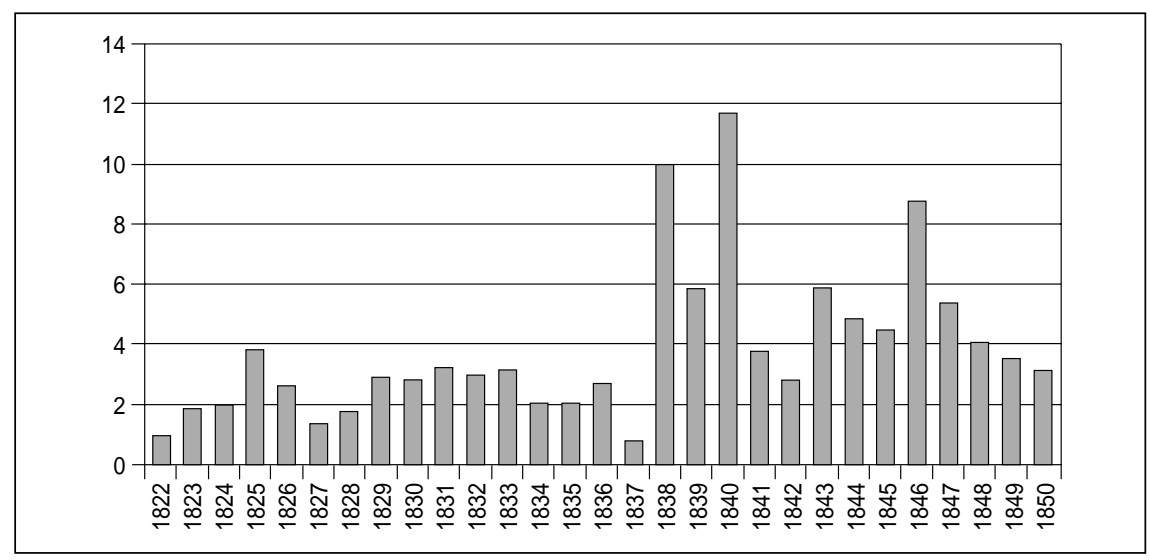

Fuente: Idem Anexo Estadístico.

la segunda mitad, más precisamente desde 1834 a 1837, y a pesar del repunte de la actividad económica que muchos testimonios permiten confirmar ${ }^{19}$, su importancia relativa vuelve a decaer. En el último año mencionado se informa que el monto cobrado corresponde a deudas de años anteriores, como si ese año se hubiera suspendido su cobro.

En el año 1838, con el inicio de la crisis fiscal por el bloqueo francés, el gobierno duplica por decreto los montos a percibir por CD, además de cobrarse los correspondientes al año anterior, por lo que la recaudación se incrementa notablemente ${ }^{20}$. Este aumento en valores absolutos se prolongará con algunos altibajos hasta 1841, a la vez que se amplifica su importancia relativa entre los ingresos totales de la provincia, llegando al 11,7 por cien en 1840. Este incremento sustancial del peso relativo de la $C D$ se encuentra menos afectado por la mejora en su recaudación que por la disminución de los ingresos aduaneros por el bloqueo francés del puerto.

El cuadro 1 refleja el período en el que se produce la caída y luego su recuperación ${ }^{21}$.

grande, como el norte. Creemos que la baja recaudación debe reflejar en parte este fenómeno. Ver detalles sobre los efectos de la sequía en Garavaglia (1998).

19 Ver Gelman y Santilli (2005).

20 ROBA 28/5/1838, pp. 57 y 58

21 Tengamos en cuenta que no se muestran desagregadas las cifras de entradas terrestres y marítimas o fluviales. Si las terrestres no disminuyeron o lo hicieron en menor proporción, como es de esperar, la caída de actividad del puerto debe ser aún mayor. 


\section{CUADRO 1}

INGRESOS DE ADUANA (en pesos papel) 1837 - 1842

\begin{tabular}{|c|c|c|}
\hline Año & Percibido & Índice \\
\hline 1837 & 9156877,00 & 100,0 \\
1838 & 4589704,81 & 50,1 \\
1839 & 2260128,81 & 24,7 \\
1840 & 5500334,56 & 60,1 \\
1841 & 36414464,66 & 397,7 \\
1842 & 31253710,69 & 341,3 \\
\hline
\end{tabular}

Fuente: Burgin (1960).

Como se ve, la reducción significó un 50 por cien en el primer año de bloqueo, un 75 por cien en el segundo, y en 1840 se produce el repunte en los últimos meses, a la par del levantamiento del sitio. También es notoria la recuperación posterior, que acompaña el salto del comercio exterior. En este marco cobró significativa importancia la percepción de la $\mathrm{CD}$ en los años de bloqueo, y se entiende la urgencia del gobierno por lograr que la Sala de Representantes modifique el régimen, como así también el empeño puesto para lograr una mejor recaudación.

A partir de la recuperación del nivel de los ingresos de aduana, la CD se acrecentó notoriamente en términos absolutos, aunque significó un más modesto nivel relativo, ubicándose entre el 3 y el 5 por cien. La excepción es 1843, pero en realidad se trata de la percepción de parte de la CD de 1842, que parece no haberse cobrado en ese año y sí en el siguiente. Pero el incremento logrado en esos años tiene que ver, en gran medida, con la mención por separado del impuesto percibido por consignaciones, que ya mencionamos con anterioridad. Veamos en el gráfico 3 en detalle cómo influyen esos números en nuestra estadística.

Aquí podemos apreciar con total claridad la importancia que el rubro de consignaciones tenía en el total de lo percibido por $\mathrm{CD}^{22}$. En varios años superó al monto obtenido por las imposiciones sobre el capital ganadero e inmobiliario de la provincia. Hacia finales de los cuarenta esa tendencia parece afirmarse, dado su aumento y la disminución absoluta del gravamen sobre los otros capitales. Como se ve en el gráfico 3 , durante el período de puerto desbloqueado del 41 al 44, el monto de consignaciones fue por lo menos el equivalente a las $2 / 3$ partes del total percibido por los otros conceptos. Pero este rubro de consignaciones disminuye fuertemente durante los años de bloqueo, para aumentar luego hasta casi duplicar, en el último año evaluado, 1850, al resto de la CD.

${ }^{22}$ Téngase en cuenta que para los períodos $1827 / 28$ y 1836/1838 no contamos con información desagregada, por lo que no evaluamos ni estimamos esa partición. 
GRÁFICO 3

RECAUDACIÓN CONTRIBUCIÓN DIRECTA EN PESOS PAPEL

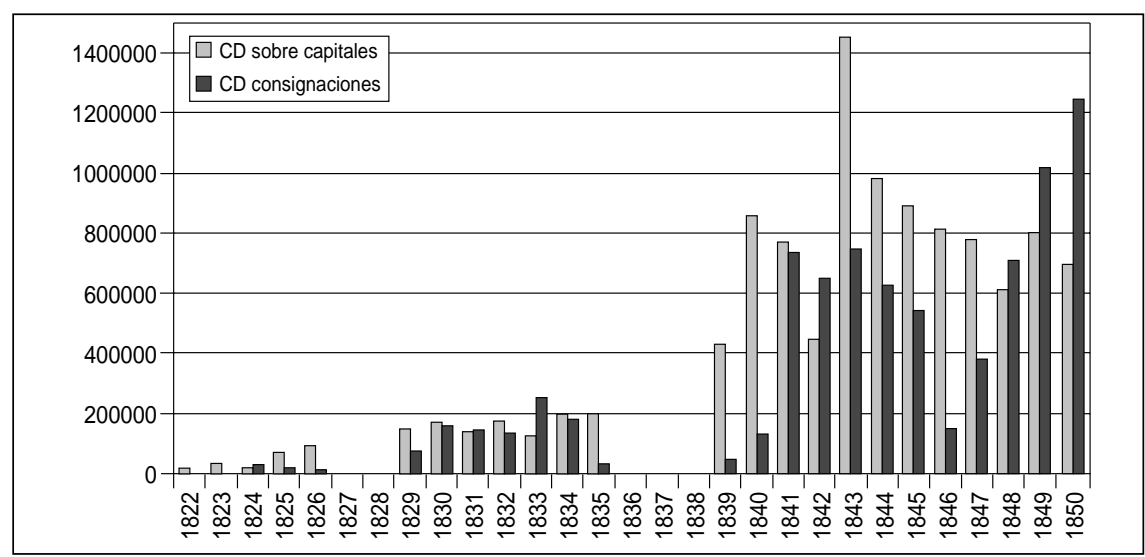

Fuente: Idem Anexo Estadístico.

En términos relativos, casi alcanza el nivel a que había llegado en 1833, un muy mal año de la CD sobre capitales.

Y, si aceptamos nuestra deducción de que a partir de 1839 esta imposición pasa a ser percibida directamente por la Aduana en el momento del ingreso de la mercadería, podemos tener una impresión directa de la magnitud de tal comercio. Desde ella podemos observar sus vicisitudes. Lamentablemente no tenemos la composición para los años previos al bloqueo de fines de los treinta como para observar la caída, pero sí podemos hacerlo con el segundo bloqueo anglo-francés del 45 al 48 . Se ejemplifica con el cuadro 2.

En primer lugar, es notable el paralelo entre los derechos de aduana y las imposiciones sobre consignaciones, lo que reafirma nuestra aseveración de que se percibía en el momento del ingreso a mercado y se la puede considerar como un impuesto más a las importaciones. En general se observa que la caída es menos abrupta que en el anterior cierre del puerto, pero la profundidad es prácticamente la misma que cinco años antes. Sin embargo, el bloqueo no fue tan perjudicial para el fisco y la economía bonaerense como lo fueron los anteriores. Tampoco las consecuencias políticas fueron las mismas ${ }^{23}$.

Es notable también cómo se refleja la disminución en la CD sobre los otros capitales, si bien el nivel hasta el cual desciende no es tan profundo. Esto estaría mostrando que un deterioro del comercio exterior arras-

${ }^{23}$ Halperin (1978). También Rosal y Schmit (2000). 
CUADRO 2

EFECTOS DEL BLOQUEO ANGLO FRANCÉS (en pesos papel) 1844 - 1850

\begin{tabular}{|c|r|c|c|c|}
\hline Año & $\begin{array}{c}\text { Derechos } \\
\text { de Aduana }\end{array}$ & Índice (*) & CD Capitales & Índice (*) \\
\hline 1844 & 29250362 & 100,0 & 981059 & 100,0 \\
1845 & 27871184 & 87,0 & 893730 & 91,1 \\
1846 & 6036121 & 24,3 & 815411 & 83,1 \\
1847 & 15025900 & 61,3 & 780565 & 79,6 \\
1848 & 28807864 & 113,7 & 614948 & 62,7 \\
1849 & 48007826 & 163,0 & 798546 & 81,4 \\
1850 & 57944483 & 199,1 & 695685 & 70,9 \\
\hline
\end{tabular}

(*) Índice $1844=100$.

Fuente: Burgin (1960)

tra una crisis general de la actividad económica, que se refleja también en el valor decreciente de los capitales en juego, a pesar de que no correspondan exactamente a la misma actividad. Ahora bien, si la CD sobre esos otros capitales se asocia moderadamente en la bajante, no lo hace a su vez en el ciclo ascendente, ya que cuando la consignación (junto a los derechos de aduana en general) casi duplica el nivel del año de partida, nuestra CD todavía estaba por debajo un 30 por cien. Esto seguramente no significa que la expansión del comercio exterior haya dejado de beneficiar al conjunto de la economía, sino que el Estado, que consigue recursos crecientes a través de los ingresos aduaneros, ha descuidado el cobro de los impuestos directos.

Veamos en el gráfico 4, la evolución general de la CD en pesos papel. También confeccionamos el gráfico 5 con los valores transformados a pesos fuertes.

En 1826/27 y 1836/38 no tenemos discriminada la recaudación de la CD sobre capitales, por lo que sólo se consigna la suma total, que incluye las dos variantes, la mencionada con anterioridad y la calculada sobre consignaciones. Además, muchos de los contribuyentes abonaban el monto correspondiente a un año en otros subsiguientes, produciéndose un efecto de escalonamiento, como también, en más de una oportunidad se decretó el traslado del vencimiento general de un año a otro, porque la coyuntura económica o política así lo requería. De tal modo se produjeron picos en determinados años que tienen que ver con esas situaciones y no con una mayor imposición por aumento de los capitales. Para minimizar este efecto, hemos insertado la media móvil de tres períodos, que suaviza precisamente esos defasajes. No hicimos lo mismo con las consignaciones, ya que éstas se abonaban en el momento del ingreso de la mercadería; además nuestro objetivo es poner de relieve precisa- 
GRÁFICO 4

CONTRIBUCIÓN DIRECTA EN PESOS PAPEL

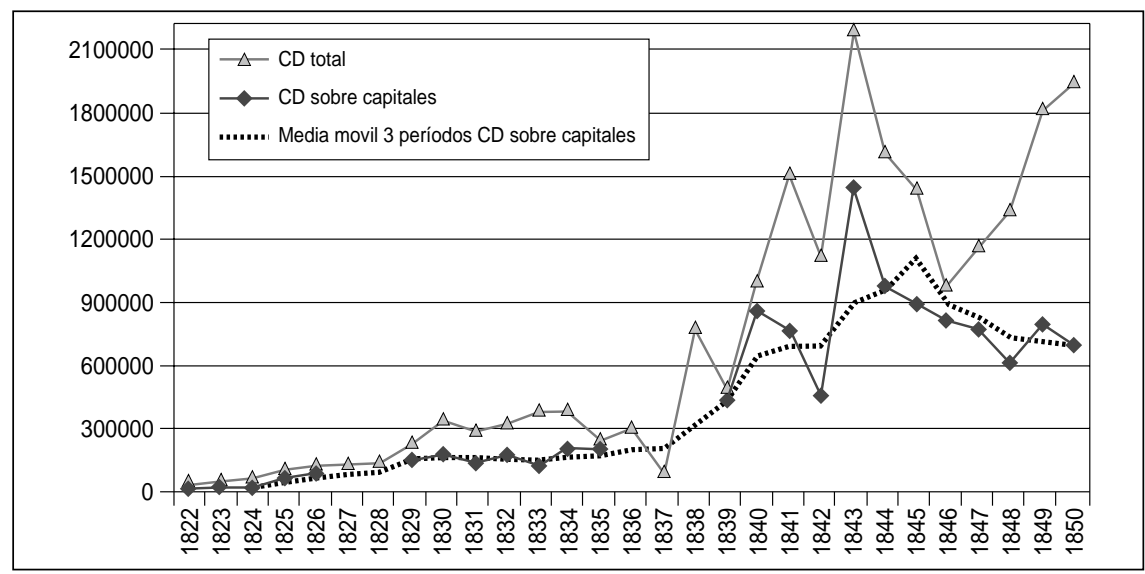

Fuente: Idem Anexo Estadístico.

GRÁFICO 5

CONTRIBUCIÓN DIRECTA EN PESOS FUERTES

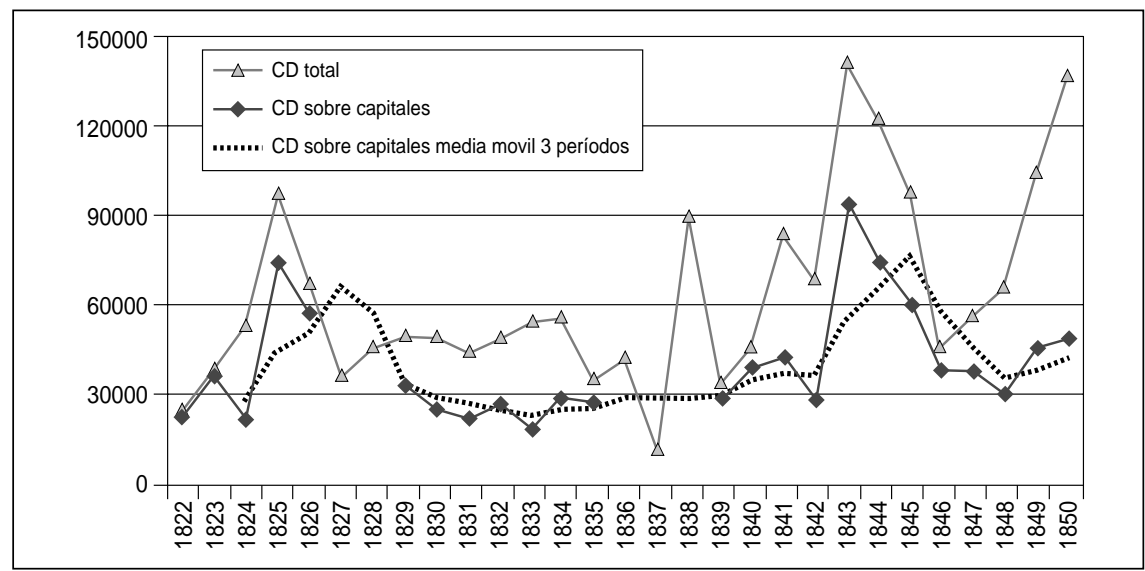

Fuente: Idem Anexo Estadístico.

mente esas diferencias de un año a otro como el resultado de las crisis provocadas por los bloqueos.

Se puede observar a partir de 1825 el éxito inicial del encargo a particulares de la percepción, ya que la recaudación en moneda constante se incrementó en forma notoria, lo que se interrumpe en 1826 y 1827 , 
avanzado el bloqueo brasilero al puerto de Buenos Aires. Sin embargo, la merma debe haber estado principalmente en las consignaciones, hecho que no podemos comprobar, ya que sólo tenemos el total no desagregado de la percepción. De cualquier manera el conjunto de la recaudación de $\mathrm{CD}$ en pesos fuertes se reduce desde 1826, también por los efectos de la emisión monetaria y la depreciación del signo con el cual los capitalistas pagan sus impuestos, como se puede apreciar en el gráfico 5.

Volviendo a los pesos papel, vemos que una vez restablecido el normal funcionamiento del puerto, el total de la recaudación retoma su camino ascendente, ahora empujado por la consignación, ya que la porción calculada sobre capitales se mantiene estable. Este estancamiento puede estar motivado por la tremenda sequía que asoló la provincia entre 1829 y 1832, pero sin duda refleja también la evasión de la que se quejaban los encargados de la percepción. Luego de 1833 comenzó una breve recuperación marcada por la superación de los avatares climáticos y por la expansión de las tierras aptas para la ganadería, a la vez que una situación política más tranquila dentro del territorio provincial. Pero está bien a la vista que las recaudaciones logradas en los años veinte no se repetían si las medimos en moneda constante y no en peso papel devaluado. Hacia mediados de la década nuevamente se inicia una fase descendente, con algunas variaciones, llegando en 1837 a la menor recaudación de todo el período en estudio.

Sucede entonces la crisis fiscal provocada por el bloqueo francés, lo que motiva la reacción del gobierno, primero duplicando los montos devengados de 1837 para 1838 y luego solicitando a la Sala de Representantes que modifique la ley de CD. En los valores incluidos en el cuadro general se nota claramente la atipicidad de 1837, por lo bajo del monto recaudado, pero más aún la de 1838 , por lo alto de la recaudación motivada por la acción del gobierno. Lamentablemente no podemos discriminar las porciones correspondientes a capitales y consignaciones, pero podemos aceptar como razonable que la CD de 1837 casi no contiene capitales, que luego se abonan en 1838, cuyo monto debe corresponder en su gran mayoría a esta última, ya que en ese año comenzó el bloqueo francés, con la consiguiente caída radical de las importaciones. Si observamos la media móvil vemos que no hay tal salto, sino una continuidad con los años previos. El salto se producirá recién en 1839, por modificación de la base legal de la imposición.

El nuevo instrumento legal, la ley del 12 de abril de $1839^{24}$, mejoró la recaudación de 1839 , pero recién se duplicará en términos de moneda corriente en el año 1840. Sin embargo la depreciación monetaria de esos

${ }^{24}$ Para un análisis de la ley, véase Gelman y Santilli (2006) 
años redujo notoriamente ese movimiento al ascenso, según vemos en el gráfico $5^{25}$. De todos modos la recaudación de $\mathrm{CD}$, aún en moneda corriente, nunca llegó al nivel esperado por los legisladores, en especial el miembro informante, Agustín Garrigós, que lo había calculado en \$ $1.000 .000^{26}$.

Ahora bien, una vez superada la coyuntura del bloqueo, aumenta fuertemente el total percibido, por la acción de la consignación ya que la porción que representa a la imposición sobre capitales vuelve a disminuir hasta llegar en 1842 al nivel de dos años antes. Pero esta situación luego se compensa con la gran subida de 1843, donde debe estar incidiendo el traslado de montos de un año a otro. Estos desniveles son un poco menos importantes en pesos fuertes porque la moneda corriente se ha revalorizado algo en esos años, según puede verse en el cuadro 3 y en el gráfico 5. En el cuadro también son visibles los estragos que hizo la inflación en la economía porteña, sobre todo en estos momentos de bloqueos, porque el gobierno se vio obligado a emitir pesos papel para solventar la escasez de recursos fiscales generada por la caída de ingresos de aduana ${ }^{27}$.

CUADRO 3

VALOR DE UN PESO FUERTE MEDIDO EN PESOS PAPEL DE LA PROVINCIA DE BUENOS AIRES

\begin{tabular}{|c|c|c|c|c|c|}
\hline Año & Valor & Año & Valor & Año & Valor \\
\hline 1825 & 1,00 & 1834 & 6,96 & 1842 & 16,31 \\
1826 & 1,69 & 1835 & 6,98 & 1843 & 15,60 \\
1827 & 3,32 & 1836 & 7,08 & 1844 & 13,19 \\
1828 & 2,92 & 1837 & 7,69 & 1845 & 14,82 \\
1829 & 4,65 & 1838 & 8,65 & 1846 & 21,30 \\
1830 & 6,93 & 1839 & 14,94 & 1847 & 20,63 \\
1831 & 6,55 & 1840 & 22,00 & 1848 & 20,29 \\
1832 & 6,56 & 1841 & 18,12 & 1849 & 17,50 \\
1833 & 7,07 & & & 1850 & 14,26 \\
\hline
\end{tabular}

Fuente: Álvarez (1929).

Con posterioridad, el nuevo bloqueo a que fue sometido el puerto de Buenos Aires provocó una caída, de la que parece que el gravamen sobre capitales no comerciales, a esta altura el único directo, sólo se recuperará parcialmente. Mientras tanto la $\mathrm{CD}$ sobre la consignación, crecerá

${ }^{25}$ Nótese que la escala del eje de ordenadas del gráfico 5 con la CD en pesos fuertes es menor que la del gráfico 4 valorada en pesos papel.

26 Ver sus apreciaciones en Estevez (1960).

27 Halperin (1978). 
inmediatamente de finalizado el bloqueo, acompañando la fuerte expansión del comercio exterior.

La buena gestión del Estado como perceptor del impuesto se debe notar más en las cifras cobradas por imposición al capital que por consignaciones, sobre todo cuando estas últimas se cobraron en la Aduana, es decir simplemente adicionándolas a los derechos de importación. Y esto es así porque para la recaudación de la primera es necesario contar, reiteramos, con un elenco administrativo que requiera las declaraciones de los contribuyentes y luego les haga pagar. Para ello el Estado tiene dos caminos posibles: o genera los funcionarios necesarios o contrata esos controles en el sector privado. Si observamos las cifras de lo cobrado durante todo el período en moneda constante por la primera de las percepciones, es notorio que, salvo los años 1843 y 1844, ninguno de los períodos alcanzó el nivel de la segunda mitad de los años veinte, cuando Manuel J. Galup se hizo cargo de su cobro. No se trata de hacer un panegírico de la gestión privada (por otra parte fueron varias las administraciones particulares de la CD y sólo la de Galup alcanzó resultados considerables); sino de mostrar las dificultades del Estado para generar los instrumentos adecuados para la administración de sus recursos. Y en ello podemos encontrar uno de los límites del proyecto de modernización fiscal.

Sin embargo, debemos reconocer que la performance de la maquinaria administrativa no fue tan deficiente en los cuarenta, ya que podría haber cobrado más si no fuera por razones políticas que disminuyeron la base imponible. En primer lugar se produjo el embargo de los bienes de la oposición, lo que eliminó a buena parte de los más ricos como contribuyentes, aunque el Estado tuvo el beneficio secundario de aprovechar su ganado para el mantenimiento del ejército. En segundo lugar se decretó la exención del impuesto a los buenos federales, es decir a todos aquellos que de una manera u otra aportaron para el triunfo de la causa luego de la crisis del sistema entre 1838 y $1840^{28}$. Si bien estos últimos provinieron en su gran mayoría de los sectores de menores recursos, su combinación con los embargados debe haberse hecho notar en la baja de la recaudación sobre los capitales ${ }^{29}$.

${ }^{28}$ Ver el detalle de los exceptuados en AGN Sala III 33-6-24. En algunos partidos cerca de la mitad de los contribuyentes fueron agraciados con la exención.

${ }^{29}$ No así en la recaudación sobre consignaciones. La ley de exenciones nunca aclara el alcance exacto de las mismas, pero indica que ellas caen en cabeza de «los ciudadanos federales de la provincia» que estaban enrolados en el ejército combatiendo a los unitarios, con el objetivo de aliviarlos en «el quebranto sufrido en sus bienes y personas». Es decir, que la desgravación estaría en cabeza de los titulares de bienes, por sus propios bienes y no por los recibidos en consignación. Además, la CD sobre consignación grava la mercadería y no al importador. En las denuncias que hace de Angelis en la Memoria citada, queda claro que al declarar la mercadería como consignación, el capitalista evitaba la imposición al giro comercial por el capital propio. 


\section{UNA Y OTRA VEZ: LA RESISTENCIA A LA IMPOSICIÓN DIRECTA Y LOS INTENTOS DE REFORMA}

Como hemos visto, la recaudación inicial de $\mathrm{CD}$ era raquítica, cifras ínfimas que reflejaban la escasa disposición de los propietarios a cumplir con sus obligaciones fiscales directas y la incapacidad del Estado para obligarlos. El Colector general de la CD no sólo reúne cantidades absolutas menores, sino que en términos relativos son las cifras más bajas de toda la serie, poniendo en evidencia las dificultades iniciales de todo sistema nuevo de impuestos, que no contaba con legitimidad entre sus sufragantes, ni el Estado contaba con los medios para imponerlo. Desde sus inicios la CD despertó las críticas de importantes propietarios. En el mismo año de su creación, se publica en El Argos una nota que la consideraba impracticable por la dificultad de establecer el valor del gravamen y la injusticia de practicar investigaciones sobre la propiedad individual ${ }^{30}$. Los riquísimos e influyentes Anchorena se contaban entre sus tempranos y más persistentes críticos ${ }^{31}$. Desde un principio J. J. de Anchorena, o luego su hermano menor Nicolás, criticaron este impuesto por la «injusticia» de gravar capitales sin tener en cuenta la renta que proporcionaban y porque - sostenían con cinismo - obligaba a los propietarios a mentir sobre sus pertenencias, generando así un problema de orden moral. Evidentemente los Anchorena expresaban un sentir más general de los propietarios más importantes, que a la vez la propia ley de $\mathrm{CD}$ amparaba, al permitir que la riqueza se calculara sobre la base de la declaración espontánea del capitalista.

Es por ello lógico también que aquéllos que defendían la necesidad de un sistema de imposición directa más eficaz, propusieran el establecimiento de disposiciones desde el Estado para medir por sus propios medios la riqueza de las personas, formando un verdadero catastro. Ya en 1823 encontramos lo que sería una de las quejas permanentes de los encargados de la recaudación: sin un censo que pueda dar cuenta de la riqueza de las personas se hacía imposible presionar a los propietarios ${ }^{32}$.

En el gobierno se empieza a discutir alternativas, que incluyen la publicación de listas de deudores del fisco en los periódicos, así como la amenaza de utilización de la fuerza pública contra aquellos que no cumplan con sus obligaciones fiscales ${ }^{33}$.

\footnotetext{
30 Nicolau, (1988: 115).

31 No sólo discutieron este tipo de impuestos, sino que al parecer pagaron muy irregularmente sus obligaciones con el fisco. Ver Carretero (1970: 169) y Nicolau (1988: 146-47).

32 Estevez (1960: 130).

33 En 1825 se publica una lista de grandes deudores en el Argos de Buenos Aires. En 1826, durante la presidencia de Rivadavia, se ordena que en el caso de deudores notificados que se resistan al pago «el jefe de policía librará orden de apremio personal contra el indi-
} 
En este sentido la iniciativa más importante que se toma a finales de 1824 es la de delegar a un particular el cobro de la CD, que es otorgada a Manuel José Galup, quien se compromete a aumentar drásticamente la recaudación a cambio de un porcentaje de lo obtenido. Para darle credibilidad a su propuesta, Galup anuncia: «empezaré por la formación de un padrón lo más exacto posible de la ciudad, sus arrabales y campaña, expresándose en él la clase de giro y capitales de los individuos sujetos a contribución», como condición para mejorar el resultado. Y parece llevarlo a cabo de manera bastante eficaz. No sólo logra incluir en las listas de "capitalistas» a casi el triple de los individuos que estaban en ellas hasta el momento ${ }^{34}$, sino que, como se vio, la recaudación sufrió un fuerte crecimiento en términos absolutos y relativos. Es verdad que bastante rápidamente la depreciación monetaria acelerada que comienza en 1826, permite a los «capitalistas» devaluar sus pagos, lo que no dejan de denunciar algunos funcionarios e intelectuales. De todos modos, a juzgar por las cifras disponibles, a partir de estos años de administración de Galup, la participación de la CD en el total de los ingresos del Estado rondaría el 2 o el 3 por cien, cuando en los años previos apenas llegaba al 1 por cien.

De cualquier manera es evidente que el nuevo sistema implementado para recaudar la CD no logra alterar el balance general del fisco y, pese al crecimiento de su recaudación recién evocado durante los años que siguen a la asunción de Galup, la tremenda caída general de los ingresos que provoca el bloqueo portugués del puerto de Buenos Aires, iniciado en 1825, pone en evidencia que ésta debe ser compensada por otros medios que los magros ingresos de la CD no logran ni siquiera inmutar. Es así que en 1826 se produce la primera emisión masiva de billetes inconvertibles por parte del Estado como forma de proveer a sus gastos, ante todo los que la propia guerra con el imperio brasileño generaba.

Nuevamente en los primeros años treinta se discuten reformas al sistema fiscal de manera sostenida.

En 1834, el gobernador interino Viamonte, teniendo como ministro al mismo M. J. García, que había implementado la reforma fiscal de 1821, intenta reforzar el sistema de contribuciones directas y debe enfrentar la oposición de grandes propietarios quienes, según algunas versiones, promueven un vacío de poder y su caída ${ }^{35}$.

viduo resistente, y si al acto e incontinente no se dispusiese a cumplir con la ley se librará para el mismo Jefe la de ejecución y embargo contra sus bienes por la cantidad adeudada...», Estevez (1960: 133 y 135).

34 Las declaraciones tramitadas por la oficina de recaudación de CD habían sido de $1.356,1.705$ y 1.122 en 1822,1823 y 1824 respectivamente. En los tres años de administración de Galup suben a 3.062, 3.001 y 4.200 entre 1825 y 1827. En Estevez (1960: 204).

35 Nicolau (1980: 161). 
Su sucesor en la gobernación, M. V. Maza, al contrario, trata de suprimir la CD, alegando su inutilidad ${ }^{36}$.

En la Sala de Representantes se genera un fuerte debate en el cual un Anchorena, para variar, critica la CD en apoyo a la iniciativa del gobierno. Mansilla por el contrario la defiende, alegando las amenazas al puerto de Buenos Aires, mientras que Baldomero García hace otro tanto, pero por razones de principio («una institución preciosa, cual es, la que manda contribuir directamente»).

Por su parte el 15/12/34 la Comisión de cuentas de la Sala de Representantes (Juan Argerich, Pedro Trapani, Agustín Garrigós) eleva un informe sobre las cuentas públicas del 28 al 32, en el cual señalan los magros resultados de la $\mathrm{CD}$ que atribuyen a la falta de padrón, sin el cual «se hacía ilusorio el impuesto». Proponían realizar entonces dicho registro sin importar los gastos, ya que así se evitaría la defraudación al Estado. Y sugerían también que se le pida información a la policía para conocer las fincas existentes y nuevas, que se consulten los datos del Almanaque de Comercio, el registro de patentes, etc.

Una intervención importante en estos debates la realiza Pedro de Angelis, el publicista italiano que terminaría por convertirse en el principal periodista de Rosas un tiempo después. En El Monitor, que dirigía por entonces, publica una serie de artículos sobre la materia, que acabaría por reunir en una obra que edita en 1834, su conocida Memoria sobre el estado de la Hacienda Pública (De Angelis, 1834). En ella critica duramente a los capitalistas que eluden el pago de la CD, ocultan sus capitales a los ojos del fisco y propone nuevamente la necesidad de realizar un censo de propiedades. Denuncia también un tema importante desde el inicio de la depreciación monetaria de 1826: los propietarios declaran sin actualizar sus capitales en períodos inflacionarios, provocando un serio perjuicio al fisco.

Por supuesto que estas intervenciones generan la oposición de varios grandes propietarios representados en la Sala, entre los cuales no falta Nicolás Anchorena ${ }^{37}$, quienes tienen fuerte influencia sobre las propuestas que elabora el gobierno. Así, la CD continúa sin mayores cambios en los años que siguen al inicio de la segunda gobernación de Rosas en 1835, excepto que desde 1836 su administración vuelve a manos de funcionarios del Estado, terminando con el ensayo iniciado con Galup diez años atrás.

36 Según Estevez no es casualidad que en paralelo a este intento Maza deje cesante al «contador de cálculo» del Estado e ideólogo de la primer CD, Santiago Wilde, el 11/10/1834. Estevez (1960: 156-57).

37 Según Nicolau (1980: 151), pertenecen a este personaje sendos artículos críticos de la Memoria de De Angelis, publicados bajo seudónimo en el periódico La Gaceta. 
Nuevamente es en el marco de una tremenda crisis fiscal, causada esta vez por el bloqueo francés del puerto que se inicia en 1838, que se vuelve a discutir la necesidad de rápidas y profundas reformas en el esquema fiscal, mejorando los ingresos que se perciben independientemente de la aduana, en especial la CD. El gobierno de Rosas intenta eludir el recurso a la emisión monetaria, a la que había asimilado como traición a la patria, y promueve primero una serie de reformas para incrementar los ingresos del Estado, afectando a veces seriamente los intereses de los propietarios. Si por un lado va a hacer suyo el principio de Anchorena de que el ahorro en los gastos del Estado es preferible a cualquier incremento en los impuestos, la baja en los sueldos de los pocos maestros que financiaba el gobierno o el congelamiento de los sueldos de los escasos empleados públicos, no logra equilibrar un rubro de gastos cuyo componente mayoritario eran los militares que se veían incrementados por las propias circunstancias bélicas que generaron la crisis fiscal. Es así que el gobierno necesita aumentar sus ingresos y decreta por un lado una reforma de la ley de enfiteusis, duplicando el canon que deben pagar los arrendatarios de tierras fiscales y promoviendo la venta de muchas de las tierras incluidas en ese sistema, a la vez que decreta en 1838 la duplicación inmediata de la tasa de la CD.

Esto obviamente genera fuertes reacciones en contra y la Junta de Representantes, que tiene reservada para sí la aprobación de toda reforma fiscal —uno de los pocos privilegios que significativamente se reservó tras el otorgamiento de la suma del poder público a Rosas en 1835-, presenta un plan alternativo al que había decretado el gobernador. Por un lado el 8/12/38 autorizó una emisión enorme de 16.575 .000 pesos en billetes, para sufragar de manera inmediata los gastos bélicos del Estado. Por el otro se terminó aprobando una nueva versión de la ley de CD el 12/4/1839 que, si bien retrotrajo las tasas a las de la ley prevaleciente antes de 1838, introdujo algunas modificaciones que se revelarían muy radicales y generarían un fuerte malestar entre los propietarios. La nueva ley eliminó todas las exenciones al impuesto, entre las que se destacaban la eliminación de los mínimos imponibles (que a esta altura y producto de la no modificación de las cifras iniciales de 1.000 y 2.000 pesos para solteros y casados y la fuerte depreciación monetaria desde 1826 se había casi licuado) y sobre todo se dispuso la inclusión en el sistema fiscal de las tierras en enfiteusis que pasarían a pagar un impuesto igual al de las tierras en propiedad. Esta última medida afectaba a los mayores propietarios que usufructuaban grandes extensiones de tierras bajo este régimen de arrendamiento, quienes, además de pagar por ese concepto una renta muy baja, estaban excluidos hasta ese momento del impuesto al capital. La otra modificación central en la ley de CD era la que disponía que ya no sería más el propio capitalista quien declaraba sus bienes (lo 
que, como vimos, había sido denunciado desde los inicios como la causa central de la baja recaudación de CD), sino que ahora se realizaría una evaluación por parte de comisiones reguladores, compuestas por los funcionarios del gobierno en cada distrito. Se trataba de un paso fundamental en la atribución de poderes al Estado para fiscalizar la capacidad contributiva de los pobladores. De esultas de esta modificación, en los meses que siguen al decreto de la nueva ley se realiza lo que sería el primer censo económico masivo en la provincia de Buenos Aires que, como hemos podido comprobar en otros trabajos, refleja de manera bastante fiel las pertenencias de más de 12.000 "capitalistas». Como ya hemos dicho, al menos la mitad de todas las Unidades Censales de la provincia son incluidas como propietarias en estas listas y hemos podido constatar que los montos establecidos tienen una relación cercana con las pertenencias de las personas, al compararlas con fuentes de tipo privada, más confiables en sus valores.

Es decir que por primera vez se lleva a cabo aquello que diversos funcionarios reclamaron como condición para el cobro de la CD y no es casual que esta ley y la actividad censal que le siguió hayan promovido un fuerte descontento entre los sectores propietarios en contra del gobierno de Rosas, al que hasta hacía poco consideraban como propio.

Aunque no podemos atribuir ese descontento sólo a estas iniciativas fiscales, es evidente que ellas jugaron un papel importante, como lo demuestra por ejemplo su utilización como argumento por parte de todos los opositores al gobierno ${ }^{38}$.

A finales de 1839 se produce un levantamiento en el sur de la campaña de Buenos Aires, los Libres del Sur, que encabeza buena parte de los sectores propietarios más ricos de esa región. En agosto de 1840 el unitario Lavalle invade la provincia desde el norte y recoge también la simpatía de los sectores más pudientes de esa zona ${ }^{39}$.

Rosas logra derrotar a todos ellos y en setiembre del cuarenta desencadena una represión de vasto alcance, que incluye el embargo de los bienes de los «salvajes unitarios». Como hemos dicho en otro lado, estos embargos afectan a casi el 10 por cien de los propietarios, especialmente a los más ricos, como se refleja en el hecho de que casi el 20 por cien de la riqueza total de la provincia es afectada a través de esas personas.

A su vez al año siguiente, el 25/5/1841, el gobierno exime de pago de CD y Patentes por el término de veinte años a todos los ciudadanos que

${ }^{38}$ Los periódicos opositores editados en Montevideo, como El Grito Argentino o Muera Rosas, hacen referencia permanente a las «injusticias» derivadas de las modificaciones a la enfiteusis, la CD, etc. A la nueva requisitoria impositiva se agregaba la imposibilidad de mantener los negocios de exportación de productos ganaderos, a consecuencia del bloqueo y diversas quejas más.

39 Gelman (2002). 
estaban bajo el servicio de las armas o habían prestado servicios a la causa, a consideración de los jueces de paz de cada partido, como forma de compensar a sus fieles seguidores, quienes habían permitido que Rosas triunfara sobre un amplio y poderoso conjunto de enemigos ${ }^{40}$.

De nuevo las circunstancias políticas ponían en derrota un intento de modificar, aunque sea parcialmente, un esquema impositivo que descansaba en gravámenes indirectos, imponiendo un poco más a los propietarios. Las propiedades de buena parte de los más ricos salieron del sistema al quedar bajo administración del Estado que las embargó y un número crecido de propietarios más modestos fue exceptuado por «servicios a la federación». Con estos cambios la CD no sólo perdió eficacia recaudadora, sino que se alteraron los principios universalistas prevalecientes en el proyecto de 1821, primando ahora la distribución de premios y castigos por parte del poder político.

De cualquier manera, el bloqueo francés había terminado en 1840 y los ingresos aduaneros habían subido a niveles incomparables, solucionando el problema fiscal del gobierno, que recuperaba así una fuente de recursos que le permitiría afianzar su autoridad y emprender también una conquista sistemática del resto del territorio, sin tener que enfrentarse para ello con los propietarios. Como se puede ver por las cifras de los años siguientes, el bloqueo de los años 45-48 no produjo consecuencias tan funestas y fue sobrellevado con regular éxito por el gobierno, sin tener que recurrir a medidas tan extremas.

\section{CONCLUSIONES}

Hemos tratado de mostrar que la reforma intentada en Buenos Aires a principios de la década de 1820, sobre todo en la propuesta original de Santiago Wilde, contenía rasgos bastante radicales de modernización fiscal, por la que se encargaba al Estado la recaudación y a su Poder Legislativo el control, proponiendo la creación de una Receptoría Fiscal dependiente de la Sala de Representantes ${ }^{41}$. Como dijimos, estas propuestas no fueron totalmente incorporadas a la reforma efectivamente

${ }^{40}$ Y esta exención, si bien afectaba a personas por lo general más humildes que los «unitarios» recién embargados, implicaba a un número muy crecido de familias. Según pudo verificar J. C. Garavaglia, luego de las crisis de estos años el nivel de reclutamiento alcanzaba a prácticamente uno de cada cuatro o cinco varones adultos, quienes eran potencialmente beneficiarios del decreto citado. Ver Garavaglia (2003). La ley del 25/5/41 en Estevez (1960: 195).

41 El punto 6..$^{\circ}$ de los objetivos del plan Wilde decía textualmente «Que se inspire al público plena confianza sobre que todo cuanto se le exija, ha de ser necesario para su servicio, y que efectivamente se ha de emplear, y se ha empleado en él», Estevez (1960: 214). 
llevada a cabo, pese a lo cual se implantó un conjunto de innovaciones de claro sello modernizador, que tenía entre sus principios fortalecer la parte de los impuestos directos sobre los indirectos. Incluso en la etapa rosista, considerada por la historiografía tradicional como la contracara del liberalismo rivadaviano, se profundizaron ciertos rasgos de centralización del Estado y modernización de la gestión fiscal como se observa con la reforma del 39 y el masivo censo de propietarios que le sigue. Este sistema se continuará en años posteriores aunque su efecto será mitigado por las excepciones de carácter político.

Sin embargo esta voluntad reformadora encontró múltiples límites, como intentamos mostrar en este trabajo. Los gobiernos de turno tuvieron que contradecir parte de esos principios y terminar adoptando la línea de menor resistencia: en los veinte con el endeudamiento y sobre todo la emisión de moneda inconvertible; a finales de los treinta aunque se buscó evitarla, se terminó emitiendo también masivamente y, finalmente, se puso en derrota el sistema de CD, ya sea por las propiedades embargadas que quedaron fuera del pago, así como los numerosos servidores de la causa federal que también fueron premiados con veinte años de excepción del pago de CD. En la nueva coyuntura de bloqueo portuario de mediados de los cuarenta ya ni siquiera se intenta eludir lo que se había comprobado inevitable. Apenas asoma la crisis de la recaudación aduanera el gobierno de Rosas emite moneda en grandes sumas para cubrir sus necesidades, sin proponerse alternativas, más tímidas o más radicales como en años pasados ${ }^{42}$. Inclusive, como vimos, los magros ingresos que se consiguen a través de la CD en los 40 , se componen en cifras muy importantes por el gravamen a los capitales en consignación, lo que transforma un impuesto inicialmente destinado a los poseedores del capital en otro que se parece mucho al impuesto aduanero (y terminan cobrando los mismos funcionarios de aduana) y se transfiere al consumidor de las mercancías así gravadas. Aquí también el hilo se cortó por lo más fino; como dijimos más arriba se convirtió una imposición directa, que podía ser enojosa para un sector de los propietarios, el de los comerciantes, en otra indirecta que castigaba al consumidor en forma inmediata, olvidando las recomendaciones de Wilde.

En definitiva, creemos haber develado la lógica que llevó a los gobiernos a mantener un sistema impositivo basado en los gravámenes de aduana, que tenía una cierta fragilidad (por la amenaza de bloqueo), que resultaba injusto porque, atendiendo a los intereses y a la fuerte presión de las clases propietarias, descargaba sobre los consumidores el mayor peso de los ingresos del fisco, pero que permitía finalmente una buena

42 Como indica Halperin (1982: 244-45), entre 1837 y 1840 la emisión cubre el 44,2 por cien de los ingresos del Estado de Buenos Aires. En 1845-48 cubre el 36,27 por cien. 
recaudación fiscal, rápida, eficiente, de fácil consecución y que no generaba mayores resistencias porque se difuminaba en la forma de inflación de los precios al consumidor. Esto le dio un tremendo poderío al Estado de Buenos Aires y no es casual que el control de las rentas aduaneras se convirtiera en el tema clave de la organización política federal de la nación argentina. La fragilidad central del modelo fiscal se encontraba en su misma fuente de recursos, la aduana: cualquier cosa que pusiera en peligro la continuidad de su actividad ponía en crisis el conjunto del sistema.

De todos modos, la modernización del sistema fiscal, aunque incompleta, quedó plasmada en el monopolio del Estado en la percepción de impuestos, en la continuidad de la CD en años posteriores, aunque ahora como impuesto territorial, y en las fiscalizaciones de las declaraciones de los contribuyentes por parte de los funcionarios ${ }^{43}$. También perduró una norma establecida en las reformas de 1821, la obligación del Ministerio de Hacienda de confeccionar presupuestos anuales que, al margen de su efectividad, fueron realizados con regularidad, sobre todo bajo el gobierno de Rosas.

\section{BIBLIOGRAFÍA}

Álvarez, J. (1929): Temas de Historia Económica Argentina. Buenos Aires: El Ateneo.

Burgin, M. (1960): Aspectos económicos del federalismo argentino. Hachette: Buenos Aires.

Carretero, A. (1970): Los Anchorena. Política y negocios en el siglo XIX, Buenos Aires, Ed. 8. ${ }^{a}$ Década.

Chiaramonte, J. C. (1991): Mercaderes del Litoral. Economía y sociedad en la provincia de Corrientes, primera mitad del siglo XIX. Buenos Aires: FCE.

CoriA, L. (1998): «Las finanzas provinciales en tiempos de Rosas», Anales de la AAEP. Mendoza.

CoRtes CONDE, R. et al. (2000): «Las finanzas públicas y la moneda en las provincias del interior (1810-1860)», Nueva Historia de la Nación Argentina, 5. Buenos Aires, pp. 507-526.

De Angelis, P. (1834): Memoria sobre el estado de la Hacienda Pública (escrita por orden del gobierno). Buenos Aires: Imprenta del Estado.

Estevez, A. (1960): «La Contribución Directa, 1821-1852», Revista de Ciencias Económicas, año XLVIII, serie IV, núm. 10, pp. 123-234.

Fradera, J. M. (2005): Colonias para después de un Imperio. Edicions Bellaterra: Barcelona.

\footnotetext{
43 En años posteriores fue obligatorio para los escribanos exigir el comprobante de libre deuda emitido por la oficina encargada de la percepción del impuesto antes de registrar un contrato de compraventa de inmuebles. Ver Santilli (2004).
} 
GARAVAGLiA, Juan Carlos (1998): «Intensidad de uso de la tierra y tasas de ocupación ganadera en la pradera pampeana (1816-1852)», en Quinto Sol Revista de historia regional, núm. 2, Instituto de Historia Regional, Facultad de Ciencias Humanas, Universidad Nacional de La Pampa, Santa Rosa.

- (2003): «Ejército y milicia. Los campesinos bonaerenses y el peso de las exigencias militares (1810-1860)», Anuario IEHS, 18, Tandil.

Gelman, J. (2002): «La rebelión de los estancieros. Algunas reflexiones en torno a los Libres del Sur de 1839», Entrepasados, 22, Buenos Aires, pp. 113-144.

Gelman, J., y SANTILl, D. V. (2002): «Una medición de la economía rural de Buenos Aires en la época de Rosas», Revista de Historia Económica, XX:1, Madrid, pp. 81-107.

- (2003): «Distribución de la riqueza y crecimiento económico. Buenos Aires en la época de Rosas». Desarrollo Económico, 43:169, Buenos Aires, pp. 75-101.

- (2004): «Las elites económicas de Buenos Aires en la época de Rosas. Patrones de inversión, movilidad y fragmentación en tiempos de cambio», Prohistoria, 8, Rosario, pp. 11-38.

- (2005): «De Rivadavia a Rosas. Expansión ganadera y distribución de la riqueza entre 1825 y 1839», Ponencia presentada en las X Jornadas Interescuelas/Departamentos de Historia, Rosario, Argentina.

- (2006): De Rivadavia a Rosas. Desigualdad y crecimiento económico en el Buenos Aires del siglo XIX. Buenos Aires, Siglo XXI Editores.

HALPERIN, T. (1978): «Bloqueos, emisiones monetarias y precios en el Buenos Aires rosista (1838-1850)», en AAVV, Historia, problema y promesa. Homenaje a J. Basadre. Lima.

- (1982): Guerra y Finanzas en los orígenes del Estado Argentino (1791-1850), Ed. de Belgrano, Buenos Aires (reeditado por Prometeo libros, Buenos Aires, 2005).

IRIGOIN, A. (2000): «Inconvertible paper currency, inflation and economic performance in early nineteenth century Argentina», Journal of Latin American Studies, 32, London, pp. 333-359.

- (2006): «Ilusoria equidad. La reforma de las Contribuciones Directas en Buenos Aires, 1850 », L. JAUREGUI (comp), De riqueza e inequidad. El problema de las contribuciones directas en América Latina, siglo XIX. México DF, Instituto Mora.

JAUREGUI, L. (comp.) (2006): De riqueza e inequidad. El problema de las contribuciones directas en América Latina, siglo XIX. México DF, Instituto Mora.

Marichal, C., y MARINo, D. (comp.) (2001): De Colonia a nación. Impuestos y política en México, 1750- 1860, El Colegio de México, México.

MYERs, Jorge (1995): Orden y virtud. El discurso republicano en el régimen rosista. Bernal, UNQ.

Nicolau, J. C. (1980): Rosas y García. La economía bonaerense (1829-35). Ed. Sadret: Buenos Aires.

- (1988): La reforma económico-financiera en la provincia de Buenos Aires (18211825). Liberalismo y economía. Fundación Bapro: Buenos Aires.

Romano, S. (2002): Economía, Sociedad y Poder en Córdoba. Primera mitad del siglo XIX, Ferreira ed., Córdoba.

Rosal, M. A., y Schmit, R. (2000): «Del reformismo colonial borbónico al libre comercio: las exportaciones pecuarias del Río de la Plata (1768-1854)», Boletín Ravignani, 20, Buenos Aires.

SÁnchez Albornoz, N (1978): Indios y tributos en el Alto Perú. Lima: Instituto de Estudios Peruanos. 
Sánchez Santiró, E.; Jauregui, L., y Ibarra, A (coord.) (2001): Finanzas y Política en el Mundo Iberoamericano. Del Antiguo Régimen a las Naciones Independientes, Universidad de Morelos, Instituto Mora, UNAM, México.

SANTILLI, D. (2004): «El papel de la tributación en la formación del Estado. La Contribución Directa en el siglo XIX en Buenos Aires», ponencia presentada en las XIX Jornadas de Historia Económica - San Martín de los Andes.

Schmit, R. (2004): Ruina y resurrección en tiempos de guerra. Prometeo: Buenos Aires. 
ENTRE LA EFICIENCIA Y LA EQUIDAD. LOS DESAFÍOS DE LA REFORMA FISCAL..

\begin{tabular}{|c|c|c|c|c|c|c|}
\hline \multirow{4}{*}{\multicolumn{2}{|c|}{ 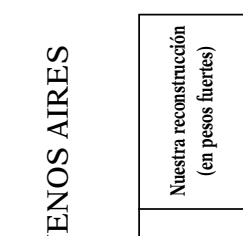 }} & 8 嵒 & 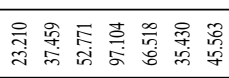 & 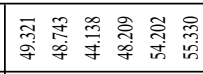 & 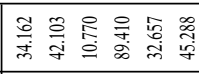 & 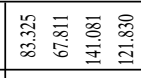 \\
\hline & & 8 8 & 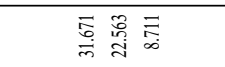 & 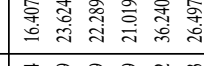 & 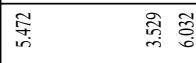 & 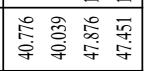 \\
\hline & & 8 & 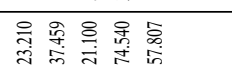 & 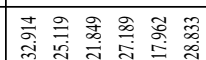 & ㄱ: & 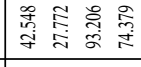 \\
\hline & & $8 \frac{\bar{g}}{9}$ & 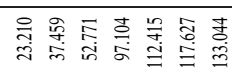 & 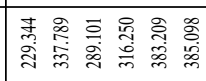 & 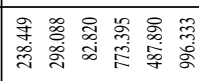 & 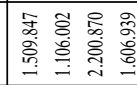 \\
\hline \multirow{2}{*}{ 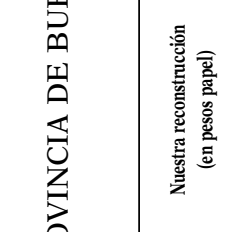 } & & 8 8. & 可总 & 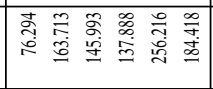 & 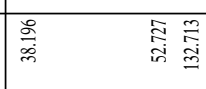 & 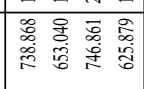 \\
\hline & & 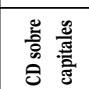 & 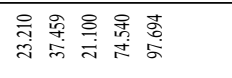 & 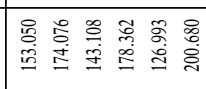 & 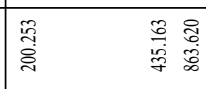 & 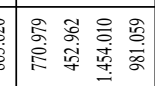 \\
\hline \multirow{16}{*}{ 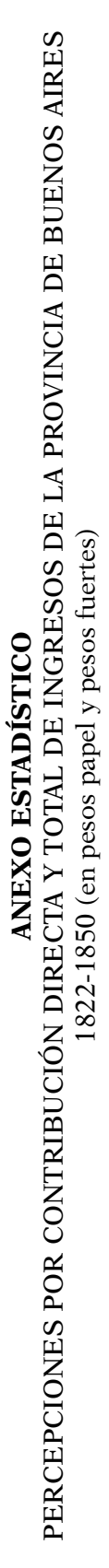 } & \multirow{2}{*}{ 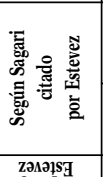 } & 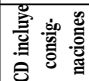 & \multirow[t]{2}{*}{ 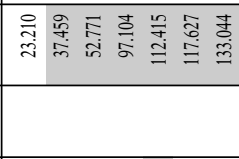 } & 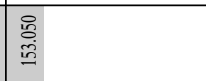 & 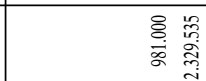 & 喿 \\
\hline & & 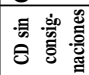 & & 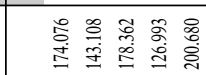 & 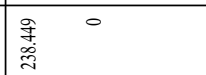 & \\
\hline \multirow{2}{*}{\multicolumn{2}{|c|}{ 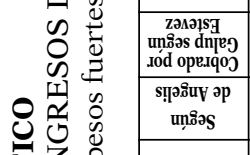 }} & 8 & & & & \\
\hline & & 8 & 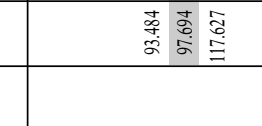 & 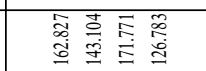 & & \\
\hline & \multirow{2}{*}{ 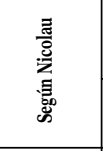 } & 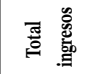 & & 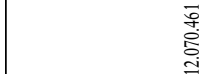 & & \\
\hline & & 8 & 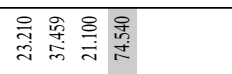 & \multicolumn{2}{|l|}{ 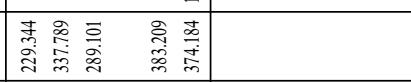 } & \\
\hline & \multirow{4}{*}{ 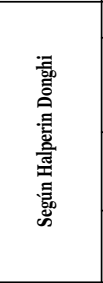 } & $\infty^{\circ}$ & $\cong$ & sis & $\overline{\bar{i}}$ & 孝 \\
\hline & & 总善 & 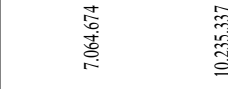 & 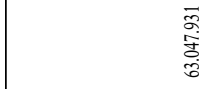 & 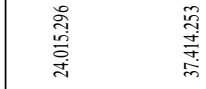 & \\
\hline & & 8 & 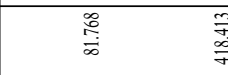 & 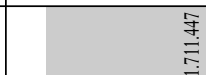 & $\begin{array}{l}\text { 表 } \\
\text { 察 }\end{array}$ & 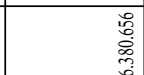 \\
\hline & & 肴 & 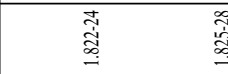 & 蒡 & 営 & 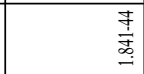 \\
\hline & \multirow{3}{*}{ 害 } & 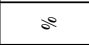 & 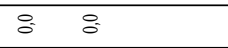 & : & $\stackrel{9}{\dddot{9}}$ & 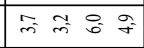 \\
\hline & & 愛总总 & 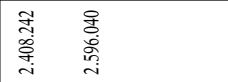 & 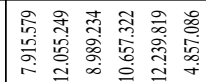 & 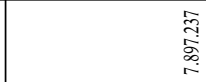 & 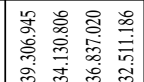 \\
\hline & & 8 & & 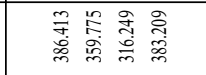 & 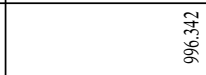 & 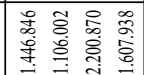 \\
\hline & \multirow{5}{*}{ 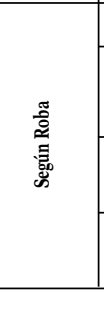 } & 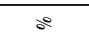 & $\stackrel{\infty}{\infty}$ & 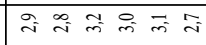 & $=\sigma^{\infty} 0_{0}^{\infty} \dot{0}^{\infty}=$ & 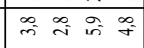 \\
\hline & & 票总 & 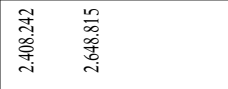 & 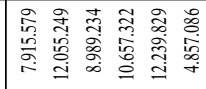 & 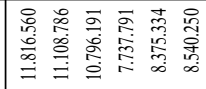 & 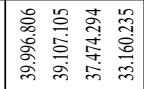 \\
\hline & & 8 & & & 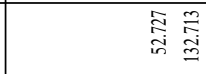 & 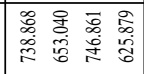 \\
\hline & & 8 & $\stackrel{8}{7}$ & 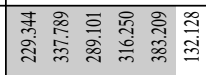 & 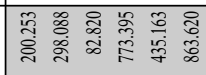 & 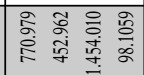 \\
\hline & & & 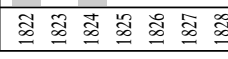 & 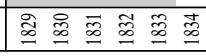 & 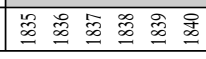 & 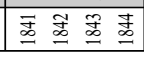 \\
\hline
\end{tabular}




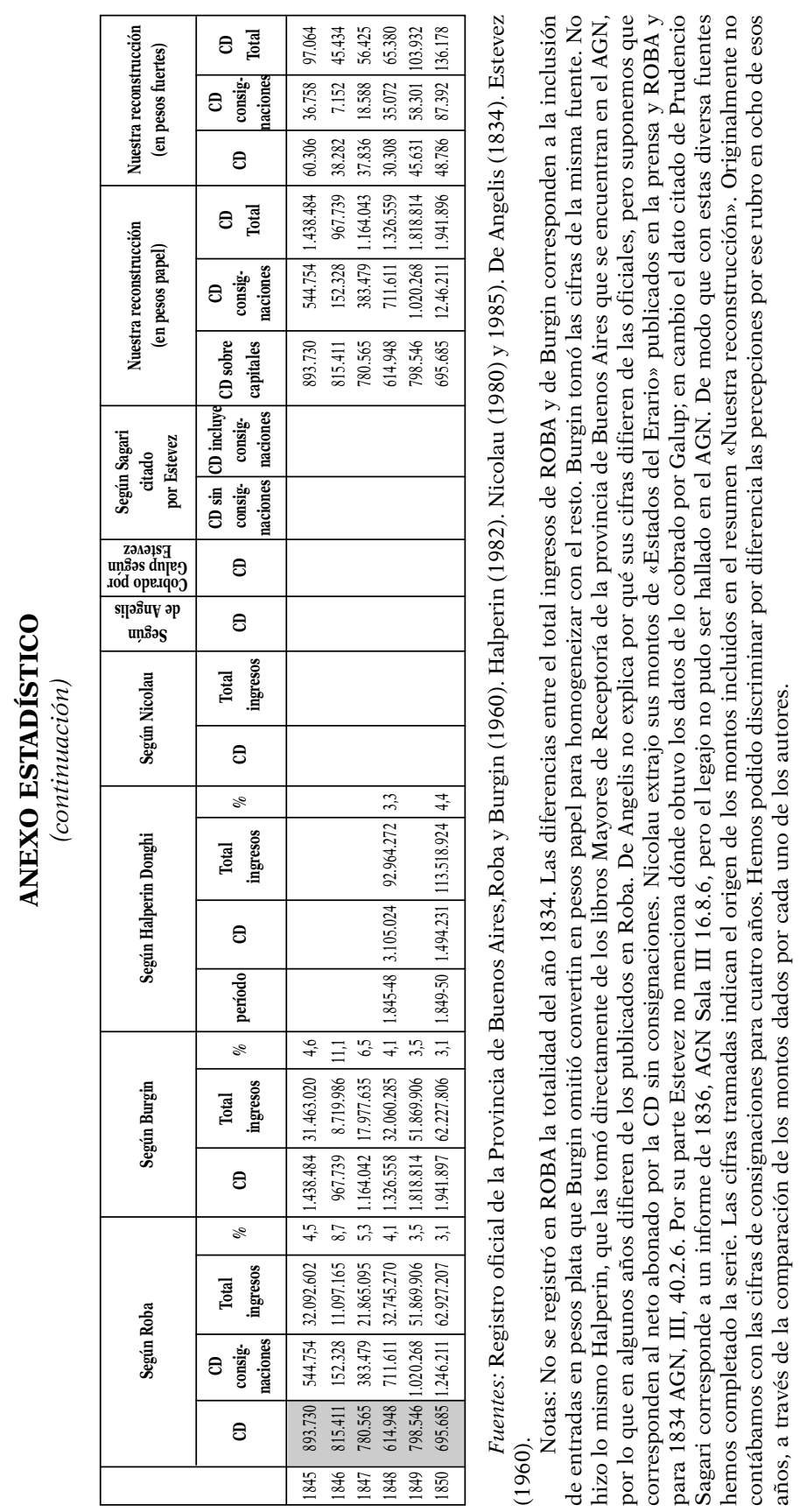

